\title{
KALIMAT MAJEMUK KOORDINATIF BAHASA JERMAN: KAJIAN TATA BAHASA TRANSFORMASI
}

\author{
Abd. Kasim Achmad \\ Fakultas Bahasa dan Sastra, Universitas Negeri Makassar \\ E-mail : abdulkasim@unm.ac.id
}

\begin{abstract}
ABSTRAK
Penelitian ini bertujuan mendeskripsikan proses transformasi kalimat majemuk koordinatif (setara) bahasa Jerman. Metode yang digunakan dalam penelitian ini adalah deskriptif. Sumber data merupakan kalimat majemuk koordinatif yang berasal dari majalah Deutschland edisi 2005-2010 dengan jumlah 6 sampel. Pengumpulan data dilakukan melalui metode simak dengan teknik catat. Data dianalisis dengan menggunakan metode distribusional dengan teknik insersi, elipsis, substitusi, dan permutasi. Hasil penelitian menunjukkan bahwa proses transformasi kalimat majemuk setara bahasa Jerman terdiri atas tiga kaidah transformasi obligatoris yaitu penambahan, pelesapan, dan subtitusi dan satu kaidah transformasi optional yakni permutasi
\end{abstract}

Kata Kunci : Kalimat Majemuk, Koordinatif, Bahasa Jerman, Transformasi

\begin{abstract}
This research aimed to describe the process of transformation of equivalent compound sentences in German. The method used in this research was descriptive. The data sources were obteined from the magazine Deutschland in editions of 2005-2010 with 16 samples. The data were collected through an observation method with note taking technique. Data were analyzed using the distributional method with the technique of insertion, ellipsis, substitution, and permutation. The results show that the transforming process of the equivalent compound sentences of German consists of three obligatory transformation rules namely addition, deletion, and substitution and one optional transformation rule namely permutation
\end{abstract}

Keywords : Compound Sentence, Equivalent, German, Transformation

\section{PENDAHULUAN}

Pembahasan mengenai analisis struktur sintaksis bahasa Jerman dapat ditemui pada buku-buku linguistik berbahasa Jerman dan beberapa penelitian lainnya. Namun, buku-buku tersebut sangat jarang bisa didapatkan di toko buku di Indonesia. Hal ini menjadi kendala yang besar bagi peminat bahasa Jerman yang ingin mempelajari linguistik bahasa Jerman dalam bidang sintaksis.

Beberapa penelitian mengenai sintaksis bahasa Jerman di Indonesia belum menyentuh pembahasan kalimat dengan menggunakan teori tata bahasa transformasi 
generatif (TTG). Contoh penelitian yang berkaitan dengan sintaksis bahasa Jerman oleh Apriyanti (2011) yang berjudul "Analisis Verba Refleksif Berpreposisi Dalam Buku Ajar Bahasa Jerman". Selain itu, Jatmiko (1991) telah melakukan penelitian dengan judul "Analisis Kontrastif Konjungsi Koordinatif dalam Bahasa Jerman dan Bahasa Indonesia dari Segi Sintaksis dan Semantis". Penelitian lainnya dilakukan oleh Sinta (2004) yang berjudul "Analisis Kalimat Pasif Bahasa Jerman dengan Teori Gramatika Transformasi Generatif: Suatu Tinjauan Sintaksis"

Kalimat majemuk bahasa Jerman dapat dianalisis dengan menggunakan teori yang banyak digunakan oleh peneliti-peneliti bahasa, yakni teori Tata bahasa Transformasi Generatif. Alasan pemilihan teori ini sebab 1) tata bahasa transformasi generatif meninjau aspek bahasa berdasarkan sudut pandang bahasa itu sendiri, serta menelaah unsur-unsur dan fungsinya dalam bahasa yang diteliti, 2) transformasi generatif mampu menjelaskan proses atau kaidah perubahan dari struktur dalam menjadi struktur luar atau permukaannya, baik dalam hal menambah, mengurangi (penghilangan), permutasi, maupun pergantian, 3) teori mampu memisahkan pengetahuan kebahasaan (linguistic competence) dengan keterampilan berbahasa (linguistic performance), 4) dapat membentuk konstruksi-konstruksi lain secara kreatif berdasarkan kaidah yang ada. Dengan kata lain, dengan teori ini kita dapat menghasilkan kalimat yang tak terhingga banyaknya karena gramatiknya bersifat generatif.

Model transformasi yang digunakan dalam penelitian ini adalah versi teori standar (Standard Theory). Pemilihan model ini dilatarbelakangi anggapan bahwa dengan teori tersebut dapat menjelaskan proses transformasi secara lengkap dan detail.

\section{TATA BAHASA TRANSFORMASI}

Kaidah tata bahasa transformasi berawal dari buku berjudul Syntactic Structure yang merupakan disertasi dari Noam Chomsky yang berasal dari Massachussets Institute of Technology, Amerika Serikat. Buku tersebut diterbitkan pada tahun 1957 sebagai kritikan terhadap teori yang dikemukakan oleh Ferdinand De Saussure (1857-1913) dan Leonard Bloomfield (1877-1950). Teori ini kemudian dikembangkan lagi oleh Chomsky dengan menerbitkan buku keduanya yakni Aspect of the Theory of Syntax pada tahun 1965. Karena pendekatan teori ini secara sintaksis tidak menyinggung makna (semantik), maka teori ini disebut juga sintaksis generatif (generative syntax). Pada tahun 1968 Chomsky mencetuskan teori extended standard theory. Keseluruhan teori tersebut termasuk dalam tata bahasa transformasi generatif berbasis transformasi. Selanjutnya, muncul teori tata bahasa transformasi generatif yang berbasis prinsip dan parameter dengan diterbitkannya buku teori penguasaan dan pengikatan (government and binding theory) pada tahun 1980 dan sebagai revisi akhir oleh Chomsky muncullah program minimalis (minimalist program) pada tahun 1995.

Kaidah transformasi memerikan tiga peranti kalimat, yaitu struktur batin, struktur lahir, dan transformasi itu sendiri (Pangaribuan, 2008:106). Struktur batin menurut Kridalaksana (2008:228) (1) output dari kaidah struktur frase dan leksikon dan input pada transformasi dan komponen semantik; (2) struktur yang dianggap mendasari kalimat atau kelompok kata, yang mengandung semua informasi yang 
diperlukan untuk interpretasi sintaksis dan semantik kalimat, dan yang tidak nyata secara langsung dari deret linier kalimat atau kelompok kata itu.

\section{KALIMAT MAJEMUK KOORDINATIF}

Kridalaksana (2008), Verhaar (2008), Chaer (2007), Parera (2009), dan Pusat Bahasa (2008) memberikan pengertian kalimat majemuk yang dapat disimpulkan sebagai kalimat yang terdiri atas dua klausa atau lebih. Pemilihan fokus kajian ini disebabkan struktur kalimat majemuk bahasa Jerman sangat kompleks dan memiliki kaidah-kaidah yang menarik untuk diteliti.

Kalimat majemuk koordinatif biasa juga disebut kalimat majemuk setara. Chaer (2007:243) memberikan pengertian kalimat majemuk koordinatif adalah kalimat majemuk yang klausa-klausanya memiliki status yang sama, yang setara, atau yang sederajat. Klausa-klausa dalam kalimat majemuk koordinatif secara eksplisit dihubungkan dengan konjungsi koordinatif seperti dan, atau, tetapi, dan lalu. Namun, tak jarang hubungan itu hanya secara implisit, artinya tanpa menggunakan konjungsi. Apabila ada unsur klausa yang sama, maka biasanya unsur yang sama itu disenyawakan atau dirapatkan. Dalam buku tata bahasa tradisional, konstruksi tersebut disebut kalimat majemuk rapatan.

Pendapat lainnya dikemukakan oleh Putrayasa (2010:55) yang memberikan pengertian kalimat majemuk setara adalah gabungan dari beberapa kalimat tunggal yang unsur-unsurnya tidak ada yang dihilangkan. Dapat juga dikatakan bahwa antara unsurunsur kalimat tunggal yang digabungkan kedudukannya setara. Secara garis besar, kalimat majemuk setara dibagi menjadi tiga bagian, yaitu (a) KMS sejalan, (b) KMS berlawanan, dan (c) KMS penunjukan. KMS sejalan adalah kalimat-kalimat yang digabungkan itu tidak berlawanan atau pengertiannya sejalan. KMS berlawanan adalah kalimat-kalimat yang digabungkan itu mengandung makna pertentangan, dan KMS penunjukan adalah bagian kalimat satu menunjuk kembali pada bagian kalimat lain.

Alek dan Achmad (2011:246) menjelaskan bahwa kalimat majemuk setara terdiri atas dua suku kalimat (klausa), atau lebih, yang bebas atau lebih. Tanda koma memisahkan suku kalimat itu jika subjeknya berbeda, jika kata penghubungnya menunjukkan pertentangan, atau jika suku kalimat itu panjang-panjang. Gagasan yang segi-seginya sama pentingnya (sejumlah kalimat tunggal) dituangkan ke dalam kalimat majemuk setara.

\section{METODE PENELITIAN}

Populasi dalam penelitian ini meliputi semua kalimat majemuk setara yang terdapat dalam majalah Deutschland edisi tahun 20052010 yang diterbitkan oleh Societät-Verlag, Frankfurt am Main bekerja sama dengan Auswärtiges Amt (Departemen Luar Negeri Jerman). Teknik pengambilan sampel yang digunakan adalah purposive sampling dengan memilih 6 kalimat majemuk pada majalah Deutschland edisi tahun 2005, 2006, 2008, 2009, dan 2010.

Metode yang digunakan dalam penelitian ini adalah metode simak dengan teknik catat sebab data penelitian berbentuk tulisan. Teknik catat yang dimaksud ialah mencatat kalimat majemuk dalam Bahasa Jerman yang terdapat pada majalah Deutschland. Data yang didapatkan dianalisis dengan menggunakan metode distribusional dengan substitusi (penggantian), insersi (penambahan), elipsis (penghilangan), dan 
permutasi (pemindahan). Proses analisis data dilakukan dengan beberapa langkah sebagai berikut; mengidentifikasi jenis kalimat majemuk koordinatif, menganalisis kaidah struktur frasa, menentukan leksikon, mendeskripsikan proses transformasi, menentukan kaidah transformasi yang berlaku.

\section{HASIL DAN PEMBAHASAN}

Beberapa kalimat majemuk setara yang diambil sebagai sampel pada penelitian ini menggunakan konjungsi und 'dan', aber 'tetapi', sondern 'melainkan' dan oder 'atau'. Kalimat majemuk setara bahasa Jerman dalam bentuk rumus dapat diuraikan seperti berikut : $\mathrm{K} \rightarrow$ Konj $\mathrm{Kn}=2$ atau lebih.

Data kalimat majemuk koordinatif yang ditemukan yaitu; (1) Eine erste Galerie steht bereits online und wird immer wieder erweitert, (2) Viele Frauen sind heute deutlich besser aussgebildet und haben gute Startchancen, (3) Wichtig war die Rolle des Staates oder die Rolle der Wirtschaft, (4) Der Campus hat in seiner inzwischen fast sechsjährigen Geschichte unsere Erwartungen nicht nur erfüllt, sondern weit übertroffen, (5) Eigentlich wollte sie mal Tierärztin werden, aber die Berufsberatung überredete sie zu einem BWL-Studium, (6) Wir haben viel Arbeit vor uns, aber wir werden es schaffen.

Kalimat majemuk setara dalam bahasa Jerman dibentuk dengan cara; 1) Penambahan konjungsi, 2) Pelesapan atau tanpa pelesapan bagian yang sama dalam kalimat, 3) Dengan atau tanpa adanya permutasi, 4) Susbtitusi.

\section{Kalimat Majemuk (1)}

Kalimat (1) pada dasarnya terdiri atas dua kalimat yang bertaraf setara atau bebas dan menggunakan konjungsi und 'dan'.
Subjek pada kalimat pertama adalah sama dengan subjek pada kalimat kedua. Struktur batin memperlihatkan hal tersebut [K [K] Eine erste Galerie steht bereits online] und [K2 Eine erste Galerie wird immer wieder erweitert ] ]. Kaidah struktur frasa (KSF) yang membentuk kalimat tersebut dijabarkan sebagai berikut. Kalimat majemuk (KM) dibentuk dengan menggabungkan dua kalimat tunggal (KT) yang dihubungkan oleh konjungsi. Struktur KT terdiri atas frasa nomina (FN) dan frasa Verba (FV). FN $\rightarrow$ Det $+\mathrm{Num}+\mathrm{N} ; \mathrm{FV} \rightarrow$ Aux + V + (Adv); Aux $\rightarrow$ (tense) (pasif); Tense $\rightarrow$ kala kini. Leksikon yang mengisi KSF tersebut adalah $\mathrm{N}=$ Galeri; $\mathrm{V}=$ stehen, erweitert (verba partisip 2); $\mathrm{Adv}=$ immer, wieder; Aux= wird (pemarkah pasif); $\mathrm{Num}=$ erste $;$ dan Konj= und .

Transformasi kalimat-kalimat tunggal tersebut diawali dengan penerapan kaidah penambahan konjungsi koordinatif und 'dan'. Selanjutnya, terjadi proses penggabungan yang melibatkan kaidah transformasi pelesapan. Pelesapan terjadi pada unsur kalimat yang sama yaitu subjek eine erste Galerie.

\section{Kalimat Majemuk (2)}

KM (2) terdiri atas dua kalimat yang bertaraf sama dan dihubungkan oleh konjungsi und 'dan'. Struktur dasar kalimat majemuk tersebut digambarkan sebagai berikut. [K [KI Viele Frauen sind heute deutlich besser ausgebildet] und [K2 Viele Frauen haben gute Startchancen]]. Unsur yang sama pada kedua kalimat tersebut adalah subjek yakni Viele Frauen. Pelesapan subjek juga berlaku pada kalimat ini. Kaidah struktur frasa pada kalimat majemuk tersebut yaitu; $\mathrm{K}$ $\rightarrow \quad \mathrm{K} 1+\mathrm{Konj}+\mathrm{K} 2 ; \mathrm{K} \rightarrow \mathrm{FN}+\mathrm{FV}$; $\mathrm{FN} \rightarrow(\mathrm{Num})+($ Adj $)+\mathrm{N}$ atau Fadj; $\mathrm{FV} \rightarrow$ Aux $+\mathrm{V}+\mathrm{FN} ;$ FAdj $\rightarrow$ Adv + Adj; Aux $\rightarrow$ Tense+(Modal); Tense $\rightarrow$ kala kini; 
dan Konj $\rightarrow$ Koordinatif. Leksikon yang mengisi kaidah struktur frasa di atas yaitu; $\mathrm{N}=$ Frauen; V=haben; ausgebildet (Partisip 2); $\mathrm{Adv}=$ heute, deutlich; $\mathrm{Num}=$ viele $; \mathrm{Adj}=$ besser, gute; dan Konj= und.

K1 pada KM 2 tersebut mengalami proses transformasi menjadi kalimat pasif. Kaidah transformasi pembentukan kalimat pasif ada dua yaitu penambahan unsur pembentuk pasif yakni sind dan kaidah permutasi. Permutasi yang dimaksud adalah pemindahan unsur verba partisip perfek ke akhir kalimat.

Seperti halnya pada kalimat majemuk (1) proses transformasi menerapkan kaidah penambahan dan pelesapan. Kaidah penambahan dengan menambahkan konjungsi koordinatif und. Kaidah pelesapan terjadi pada unsur subjek yang sama ialah viele Frauen.

\section{Kalimat Majemuk (3)}

Struktur dalam kalimat tersebut terdiri atas dua kalimat majemuk seperti diuraikan berikut ini; [K [K1 Die Rolle des Staates war wichtig] oder [K2 Die Rolle der Wirtschaft war wichtig]]. KSF yang membangun kalimat tersebut adalah $\mathrm{K} \rightarrow \mathrm{K} 1+\mathrm{Konj}+\mathrm{K} 2$; $\mathrm{K} \rightarrow \mathrm{FN}+\mathrm{FV} ; \mathrm{FN} \rightarrow$ Det+N + Det $+\mathrm{N}$; $\mathrm{FV} \rightarrow$ Aux $+\mathrm{V}+$ Adj; Aux $\rightarrow$ tense; Tense $\rightarrow$

lampau; dan Konj $\rightarrow$ koordinatif. KSF tersebut diisi oleh leksikon sebagai berikut; Det $=$ die $($ Feminim); des (Genetif, Maskulin) der (Genetif, Feminim); N= Rolle, Staat, Wirtschaft; $\mathrm{V}=$ war (bentuk lampau dari sein); $\mathrm{Adj}=$ wichtig; dan Konj= oder .

Terdapat dua unsur yang sama yaitu pada frasa nomina die Rolle dan frasa verbanya. Unsur pertama ialah frasa nomina die Rolle tidak mengalami penghilangan atau pelesapan sebab masing-masing frasa nomina tersebut diikuti oleh kaidah pembentukan kasus genetif (posesif) yang berbeda. Kaidah pembentukan kasus genetif yang terjadi pada kalimat pertama adalah diikuti oleh nomina berjenis maskulin sedangkan yang kedua diikuti oleh nomina berjenis feminim. Unsur yang mengalami penghilangan adalah unsur yang kedua yakni frasa verba. Unsur tersebut memegang peran dan fungsi yang sama pada kedua kalimat tersebut sehingga mengalami penghilangan. Transformasi yang selanjutnya terjadi pada kalimat tersebut adalah permutasi. Permutasi yang terjadi ditandai dengan adanya pertukaran tempat antara frasa nomina dengan konstituen adjektiva.

\section{Kalimat Majemuk (4)}

Struktur dasar kalimat di atas dapat dibagi ke dalam dua kalimat yang setara seperti berikut; [K [K1 Der Campus hat in seiner inzwischen fast sechsjährigen Geschichte unsere Erwartungen nicht nur erfüllt ] sondern [K2 Der Campus hat in seiner inzwischen fast sechsjährigen Geschichte unsere Erwartungen weit übertroffen ] ]. Kaidah struktur frasa dari kalimat tersebut adalah; $\mathrm{K} \rightarrow \mathrm{K} 1+\mathrm{Konj}+\mathrm{K} 2$; $\mathrm{K} \rightarrow \mathrm{FN}+\mathrm{FV} ; \mathrm{FN} \rightarrow((\mathrm{Det}+\mathrm{N})(\mathrm{FP}+\mathrm{Adv}+$ $\operatorname{Adj}+\mathrm{N})) ; \mathrm{FV} \rightarrow \mathrm{Aux}+\mathrm{V}+\mathrm{FN}+(\mathrm{Neg})+$ (Adj); FP $\rightarrow$ Prep + FN; Aux $\rightarrow$ Tense; Tense $\rightarrow$ kala kini; dan Konj $\rightarrow$ koordinatif. Leksikon dari kaidah struktur frasa tersebut dijabarkan sebagai berikut; Det $=$ der; $\mathrm{N}=$ Campus, Geschichte, Erwartungen; $\mathrm{Adv}=$ inzwischen, fast, nur; Adj= sechsjährigen, weit; Aux = hat (pemarkah perfekta); V= erfüllt, übertroffen (partisip 2); Neg= nicht; Prep $=$ in (datif); Pron= seiner (posesif, datif), unsere (posesif, akusatif); dan Konj= sondern.

Dari penjabaran tersebut terlihat bahwa unsur yang sama pada kedua kalimat tunggal tersebut adalah Der Campus hat in seiner inzwischen fast sechsjährigen Geschichte unsere Erwartungen. Unsur tersebut terdiri atas subjek yakni Der Campus, 
auxiliary yang merupakan pemarkah perfekta hat, frasa preposisi in seiner inzwischen fast sechsjährigen Geschichte, dan objek yakni unsere Erwartungen. Unsur yang sama tersebut akan mengalami pelesapan pada saat proses transformasi.

\section{Kalimat Majemuk (5)}

Struktur dasar kalimat tersebut dapat dibagi ke dalam dua kalimat yang setara seperti berikut; [к [к1 Sie wollte eigentlich mal Tierärztin werden ] aber [к2 die Berufsberatung überredete sie zu einem BWLStudium] ]. KSF yang mengisinya adalah; $\mathrm{K} \rightarrow \mathrm{K} 1+\mathrm{Konj}+\mathrm{K} 2 ; \mathrm{K} \rightarrow \mathrm{FN}+\mathrm{FV}$; $\mathrm{FN} \rightarrow$ Pron, FP, (Det) $+\mathrm{N}$; FV $\rightarrow$ Aux $+\mathrm{V}+$ $(\mathrm{Adv})+(\mathrm{FN})+(\mathrm{FN}) ; \mathrm{FP} \rightarrow$ Prep $+\mathrm{FN}$; Aux $\rightarrow$ tense; Tense $\rightarrow$ kala lampau; dan Konj $\rightarrow$ koordinatif. Leksikon dari kaidah struktur frasa tersebut dijabarkan sebagai berikut; Det= die, einem; $\mathrm{N}=$ Tierärztin, Berufsberatung, BWL-Studium; Adv = mal, eigentlich; $\mathrm{Aux}=$ wollte; $\mathrm{V}=$ werden, überredete (kala lampau dari überreden); Prep $=z u$ (datif); Pron= sie; dan Konj $=$ aber .

Dari penjabaran di atas terlihat bahwa hanya terdapat satu unsur yang sama ialah pronomina sie. Akan tetapi unsur tersebut tidak memenuhi syarat untuk mengalami proses pelesapan sebab pronomina tersebut memiliki fungsi dan peran yang berbeda. Pada kalimat pertama sie berfungsi sebagai subjek sedangkan pada kalimat kedua berfungsi sebagai objek akusatif. Transformasi opsional yang berlaku pada data kalimat majemuk di atas berupa transformasi permutasi yang terjadi pada kalimat pertama. Kalimat Majemuk (6)

Struktur dasar kalimat (6) dapat dibagi ke dalam dua kalimat yang setara seperti berikut; [K [K1 Wir haben viel Arbeit vor uns ] aber [К2 wir werden viel Arbeit vor uns schaffen ] ]. KSF yang mengisinya terdiri atas; $\mathrm{K} \rightarrow \mathrm{K} 1+\mathrm{Konj}+\mathrm{K} 2 ; \mathrm{K} \rightarrow \mathrm{FN}+\mathrm{FV}$; $\mathrm{FN} \rightarrow$ (Pron) $(\mathrm{Num}+\mathrm{N})(\mathrm{FP}) ; \mathrm{FV} \rightarrow \mathrm{Aux}+\mathrm{V}$ + FN; FP $\rightarrow$ Prep + pron; Aux $\rightarrow$ tense; Tense $\rightarrow$ kala kini; dan Konj $\rightarrow$ koordinatif. Leksikon dari kaidah struktur frasa tersebut dijabarkan sebagai berikut; Pron= wir, uns, es; $\mathrm{Num}=$ viel $; \mathrm{N}=$ Arbeit $;$ Aux = werden $; \mathrm{V}=$ haben, schaffen; Prep= vor (datif); dan Konj= aber.

Pada kalimat tersebut terdapat dua unsur yang sama yaitu pronomina wir dan frasa nomina viel Arbeit vor uns. Walaupun pronomina wir pada kedua kalimat tunggal tersebut memiliki fungsi dan peran yang sama namun tidak akan mengalami penghilangan pada proses transformasi menjadi kalimat majemuk. Hal ini disebabkan kedua kalimat tunggal tersebut merupakan kalimat pertentangan sehingga apabila pronomina pada kalimat kedua dihilangkan, maka bentuk kalimat majemuknya tidak akan berterima.

Unsur yang sama berikutnya adalah pada frasa nomina (FN) viel Arbeit vor uns. Namun FN tersebut tidak akan mengalami pelesapan atau penghilangan karena dengan penghilangan FN tersebut pada kalimat kedua maka hasil pembentukan kalimat majemuk tidak akan berterima. Ketidakberterimaan tersebut disebabkan sifat ketransitifan verba schaffen yang menuntut hadirnya objek langsung. Kaidah yang mungkin terjadi pada FN tersebut adalah substitusi. Melalui substitusi, FN pada kalimat kedua dapat digantikan dengan pronomina yang tepat untuk menggantikan FN tersebut sehingga bentuk kalimat akan menjadi berterima. Bentuk pronomina yang tepat untuk mengisi FN tersebut adalah es 'itu' sebab bentuk tersebut dapat mewakili keseluruhan konstituen pada FN kalimat kedua. 


\section{KESIMPULAN DAN SARAN}

Proses transformasi kalimat majemuk setara dalam bahasa Jerman melibatkan dua atau lebih kalimat tunggal yang bertaraf setara. Terdapat empat macam konjungsi koordinatif yang digunakan, yaitu und 'dan', aber 'tetapi', sondern 'melainkan' dan oder 'atau'. Kaidah transformasi yang berlaku pada transformasi kalimat majemuk setara terdiri atas kaidah transformasi obligatoris yaitu penambahan (konjungsi), pelesapan (unsur kalimat yang sama), dan subtitusi (pronominalisasi). Kaidah transformasi optional adalah permutasi (FN dan FAdj).

\section{DAFTAR PUSTAKA}

Alek dan Achmad. 2011. Bahasa Indonesia untuk Perguruan Tinggi. Edisi Pertama, Cetakan Kedua. Jakarta: Kencana Prenada Media Group.

Apriyanti, Dita Di. 2011. Analisis Verba Refleksif Berpreposisi Dalam Buku Ajar Bahasa Jerman (Skripsi). Bandung: Universitas Pendidikan Indonesia.

Chaer, Abdul. 2007. Linguistik Umum. Cetakan Ketiga. Jakarta: PT Rineka Cipta.

Jatmiko, Triyogo. 1991. Analisis Kontrastif Konjungsi Koordinatif dalam Bahasa Jerman dan Bahasa Indonesia dari Segi Sintaksis dan Semantis. (Skripsi). Universitas Indonesia.

Kridalaksana, Harimurti. 2008. Kamus Linguistik. Edisi Keempat. Jakarta: PT. Gramedia Pustaka Utama.

Pangaribuan, Tagor. 2008. Paradigma Bahasa. Graha Ilmu: Yogyakarta.
Parera, J. D. 2009. Dasar-Dasar Analisis Sintaksis. Jakarta: Erlangga.

Pusat Bahasa. 2008. Kamus Bahasa Indonesia. : Jakarta: Pusat Bahasa.

Putrayasa, Ida Bagus. 2010. Analisis Kalimat (Fungsi, Kategori, dan Peran). Bandung: PT. Refika Aditama.

Sinta, Rahayu. 2004. Analisis Kalimat Pasif Bahasa Jerman dengan Teori Gramatika Transformasi Generatif Suatu Tinjauan Sintaksis. (Skripsi). Universitas Indonesia.

Verhaar, J. W. M. 2008. Asas-Asas Linguistik Umum. Cetakan keenam. Yogyakarta: Gadjah Mada University Press. 